\title{
M. Amiri, B. Genito, M. Moini, M. Mahmoudi, B. Khosravi, G. Maresca, E. Cocca. Bishapur and its territory (Fars, Iran). Second interim report of the 2013 archaeological campaign (November)
}

\section{Sébastien Gondet}

\section{OpenEdition}

\section{Journals}

Édition électronique

URL : http://journals.openedition.org/abstractairanica/41516

DOI : 10.4000/abstractairanica.41516

ISSN : 1961-960X

Éditeur :

CNRS (UMR 7528 Mondes iraniens et indiens), Éditions de l'IFRI

Référence électronique

Sébastien Gondet, « M. Amiri, B. Genito, M. Moini, M. Mahmoudi, B. Khosravi, G. Maresca, E. Cocca. Bishapur and its territory (Fars, Iran). Second interim report of the 2013 archaeological campaign

(November) », Abstracta Iranica [En ligne], Volume 34-35-36 | 2017, document 9, mis en ligne le 15 juillet 2016, consulté le 05 octobre 2020. URL : http://journals.openedition.org/abstractairanica/41516 ;

DOI : https://doi.org/10.4000/abstractairanica.41516

Ce document a été généré automatiquement le 5 octobre 2020.

Tous droits réservés 


\section{Amiri, B. Genito, M. Moini, M. Mahmoudi, B. Khosravi, G. Maresca, E. Cocca. Bishapur and its territory (Fars, Iran). Second interim report of the 2013 archaeological campaign (November)}

\section{Sébastien Gondet}

\section{RÉFÉRENCE}

M. Amiri, B. Genito, M. Moini, M. Mahmoudi, B. Khosravi, G. Maresca \& E. Cocca. « Bishapur and its territory (Fars, Iran). Second interim report of the 2013 archaeological campaign (November) ». Newsletter di Archeologia CISA, 5, 2014, p. 123-196.

Les AA. publient ici deux rapports sur des campagnes de prospections topographiques effectuées sur le site de Bīšāpūr et ses alentours immédiats par une équipe iranoitalienne en 2012 et en 2013. Dans le premier article (2013), après une première partie consacrée à la méthodologie et à la présentation des grandes problématiques concernant cette fondation royale sassanide du sud du Fars occupée jusqu'à l'époque islamique, les AA. présentent les premiers résultats de relevés et d'études du matériel de surface dans 17 secteurs de la ville considérés comme stratégiques. L'exposé se conclue sur des observations concernant la topographie urbaine du site. Les AA. mentionnent l'existence de zones libres de construction à l'intérieur de l'enceinte fortifiée et suggèrent la présence de jardin intra-muros ce qui conduit les AA. à une digression sur l'existence de paradis à Bīšāpūr. On notera aussi des observations sur l'impact de la fondation de la ville sur son territoire avec la mention de plusieurs 
réseaux de qanāts et de voies de circulation donnant accès à la ville par des portes repérées en surface. Le second article (2014) ajoutent 15 autres secteurs d'observations à ceux publiés en 2013. Depuis il semble que cette mission n'ait pas pu se poursuivre.

2 Les données publiées sont brutes et parfois difficiles à appréhender. Elles permettent toutefois d'élargir notre vision de la ville et d'aborder la question de la topographie urbaine de Bǐšāpūr alors que les études antérieures, souvent très partiellement publiées, se sont presque toujours concentrées sur les constructions monumentales sassanides.

\section{Ce compte rendu concerne également la référence $n^{\circ} 8$ :}

4 M. Amiri, B. Genito, M. Moini, M. R. Mahmoudi, B. Khosravi, G. Maresca \& E. Cocca. «Bishapur and its territory (Fars, Iran). First interim report of the 2012 archaeological campaign ». Newsletter di Archeologia CISA, 4, 2013, p. 1-45.

\section{AUTEURS}

\section{SÉBASTIEN GONDET}

CNRS, Paris 